\title{
The Impact of Population Aging on the Industrial Value-Added Rate of China
}

\author{
Li Lin \\ Shang Hai University, China \\ tjpulinli@163.com
}

Keywords: Industrial value-added rate; Population aging rate; Total factor productivity

\begin{abstract}
The industrial value-added rate(VAR) is an important index to measure the industrial development level of a country. It will be affected by many factors, among which the gradually increase of the population aging rate is of great importance and will inevitably affect the industrial VAR. This paper conduct an extensive research on the impact of population aging on the industrial VAR, and investigate the effect of population aging on the industrial VAR of labor-intensive industries, capital-intensive industries and technology-intensive industries from different resource concentrations. The results show that the impact of population aging rate on industrial VAR is a quadratic relationship. Above a certain percentage, all types of industries will decline as the rate of aging increases. When the industrial VAR reach its peak point, the labor-intensive industries have the lowest rates of aging and the most technology-intensive ones. In order to promote the continuous increase of industrial VAR, it is an important way to vigorously develop the level of science and technology and increase the total factor productivity.
\end{abstract}

\section{Introduction}

China is a industrial powerhouse, but it is "big but not strong". However, it is undeniable that China is still in the process of industrialization and has a long way to go when compared with developed countries. China remains only in the third tier of global industry, in which service industries, science and technology are still in low level. Industry is the pillar industry of a country's national economy and the backbone of economic growth in various countries and regions. Therefore, it is a long-term task to improve the quality of industrial development in China.

The industrial VAR, which benefits from the convenience of its calculation, can reflect the level of industrial development in our country. Therefore, the empirical studies have been applied more and more widely in recent years. The policy that called "Made in China 2025" was issued by the State Council,in which they mentioned that the industrial VAR in 2020 will be $2 \%$ higher than in 2015 and 4\% higher in 2025 than in 2015. The industrial VAR is used to analyze the efficiency of industrial production. Although the contribution of capital, labor and other factors of production to efficiency improvement is not considered separately, the industrial profitability can be measured, which is one of the effective indicators to comprehensively reflect the industrial upgrading. Shen Lisheng and Wang Heng (2006) ${ }^{[1]}$ studied the VAR of China in 2000 and compared it with several developed countries in the same period. Their result shows that the VAR of our country is only half of that in developed countries, which represent that in order to obtain the same output, China should double its intermediate product more than that of developed countries. Although China's GDP has surpassed Japan to become the second-largest economy in the world, its acquisition at the same time also pays the price of over-consumption of resources and destruction of the environment. The formulation of the target of industrial value added rate can reduce the input of intermediate products and effectively promote the industrial transformation so that the manufacturing of China gradually becomes the creation of China.

According to the National Bureau of Statistics, industrial GDP accounted for one-third of the national GDP, which is the highest among all industries in 2016. Industrial VAR is an important indicator to measure a country's industrial level. Analysis of the impact of various factors on the industrial VAR and the development of effective measures based on China's national conditions are 
important steps to the successful implementation of "Made in China 2025". Therefore, this article analyzes the factors affecting the industrial VAR of our country, meanwhile exploring the various factors on the specific impact of different resource-intensive industries from the different resource-intensive industries.

\section{The literature review}

The industrial VAR refers to the final result of enterprises' production activity expressed in monetary form during the reporting period. It is the total result of the total productive activity of the industrial enterprise after deducting the value of the material products and purchased labor consumed or transferred in the production process Balance. From the perspective of production principle:

\section{Value Added = Total Output - Intermediate Input + VAT to be accrued; VAR = Value Added / Total Output.}

Gross industrial output refers to the total output of industrial final products and labor-service activities produced by the industrial enterprises in the report period in the form of money, which is the total output of the industrial enterprises. Therefore, in the case of a certain total output value, the less intermediate inputs of raw materials, energy consumption and remuneration for laborers are, the higher the industrial added value is. That is to say, the high VAR of the enterprise output means less intermediate products, the added value of output is higher. If our blind pursuit of gross output value of enterprises and ignore the economic benefits of production, intermediate input costs remain high, it is difficult to level up the rate of increase.

Different scholars have different opinions on the factors that affect the rate of industrial VAR. According to the C-D function, we know that the source of long-term economic growth comes from technological progress. Therefore, technology will have an impact on the rate of industrial VAR. Keun Lee and Byung-Yeon Kim (2009) [2] studied the effect of technology and higher education on value added. According to the estimation of generalized matrix, the effect of technology and higher education on value added varies greatly among different income countries. Higher-income countries have a greater effect on value added than higher-technology countries, while lower-income countries have a low role. Eric WK, Tsang and Paul SI Yi et al. (2008) [3] found that the contribution of technological progress to the added value of different industries is different. Specifically, the contribution of technology to high-tech industries is obviously higher than low-tech industries. Contribution is higher than domestic enterprises. By studying the high-tech industries of high-income countries such as the United States, Japan and South Korea ,Wu Wenhao (2013)[4]concluded that the high VAR of technology in various countries generally declines. At the same time, he pointed out that the transformation and upgrading of industries as well as the application of emerging technologies can restrain the rate of increase in value to a certain extent. It is always the key to lead the industry to master the core technologies of key industries. It can be seen that the vast majority of scholars agree that the role of technological progress is only divided on the degree of impact of technological progress. If in some industries or production sectors, enterprises supply low-tech, homogeneous products with low barriers to entry, lower gross profit margins and a correspondingly lower rate of industrial added value. Conversely, in some areas, due to the existence of barriers to entry and the formation of a monopoly, enterprises will have the initiative to gain a competitive advantage in order to obtain a higher gross profit margin. The highest industrial VAR in the United States, which is among the highest in the world, relies on advanced technology. Therefore, technology plays an important role in the rate of industrial added value.

All the above studies illustrate the impact on the industrial VAR from the aspects of technology. We believe that the age structure of the population is also a factor that can not be neglected. Changes in the population age structure, especially the irreversible increase in the rate of aging caused by a shortage of labor supply and the decline in labor force participation will make the cost of labor increased, consequently lead to the increment of prices of raw materials, energy and other 
intermediate inputs, thus influencing the increasing Rate. Firstly, the change in the population age structure will lead to a decline in the savings rate. Higgins and Williamson (1997) [5] conducted empirical studies by selecting data from 16 countries and regions in the middle of the 20th century in Asia. The conclusion shows that the dependency ratio of young people and the dependency ratio of the elderly leads to a lower saving rate .The higher dependency ratio of youth dependency ratio on saving is greater than the inhibitory effect on investment, while the higher dependency ratio of elderly dependency ratio on investment is greater than the inhibition on saving. Savings are closely linked with investment. Changes in savings rates will inevitably have an impact on investment, which in turn will have an impact on the development of industrial enterprises. Secondly, the irreversibility of an aging population led to a reduction in the supply of labor costs and a decrease in the labor force participation rate. As a result, the labor costs of China's industry have entered an accelerated channel of growth. The rising costs will lead to the loss of cheap labor in traditional manufacturing industries (Luo Laijun, 2012) [6]; the source of new economic growth will increasingly depend on human capital accumulation and technological innovation capability (Cai and 2005)[7]. The drop in savings and the rise in labor costs will put tremendous pressure on our industry, especially labor-intensive industries, and forcing some labor-intensive enterprises to collapse or transform. At the same time, if the quantity of labor supply changes, capital and technology can become cheaper if they can not change in proportion year-on-year to the same level of production factors such as capital and technology, and it is possible to promote capital-intensive and Technology-intensive enterprises restructuring and upgrading. Li Zhongjian (2015) [8] pointed out that raising the income level of laborers will not only reduce the competitiveness of labor-intensive industries, but also help improving the quality of laborers and further promoting the optimization of industrial structure. As China has stepped into the age of population aging, it is particularly important to study the impact of changes in the age structure of the population on the rate of industrial added value.

\section{Model Introduction}

We took advantage of research convenience, with reference to the basic assumptions of Fan Jin (2017) ${ }^{[9]}$

Gross output is co-produced with capital and intermediate inputs and enters the aggregate output function as Cobb-Doglas. Here is Jane

Standardize labor supply as 1. Suppose there is only two uses of total output in a society: investment and consumption. Investment is the next phase of the input. Then $Y_{t}=(1-x) Q_{t}$, where $x$ is part of the total output used as an intermediate input, $0<x<1, x$ can be called the intermediate input coefficient, the VAR $v$ is equal to $1-x$.

Assume that the savings rate, depreciation rate, and technology are exogenously given.

According to the above assumptions, the production process of simplified economic activities can be expressed as:

$$
q_{t+1}=k_{t+1}^{\alpha}\left[(1-v) q_{t}\right]^{1-\alpha}
$$

Of which: $q_{t}$ for the total output, $k_{t}$ for the capital stock, $v$ for theVAR. The input coefficient in the middle is $(1-v)$, so $(1-v) q_{t}$ in the formula (1) represents the part invested in the middle.

The form of capital movement is:

$k_{t+1}-k_{t}=\mathrm{sv} q_{t}-(n+\delta+g) k_{t}$

Where: $\mathrm{s}$ is the saving rate, $n$ is the population growth rate, $\delta$ is the depreciation rate, $g$ is the technological progress rate.

According to (1) and (2), we can get the total output of the exercise:

$q_{t+1}-q_{t}=k_{t+1}^{\alpha}\left[(1-v) q_{t}\right]^{1-\alpha}-q_{t}$

The formula (2) into equation (3) available: 


$$
q_{t+1}-q_{t}=\left[\operatorname{sv} q_{t}-(n+\delta+g) k_{t}+k_{t}\right]^{\alpha}\left[(1-v) q_{t}\right]^{1-\alpha}-q_{t}
$$

According to the difference equation:

$$
\begin{gathered}
\Delta k_{t}=\operatorname{sv} q_{t}-(n+\delta+g) k_{t} \\
\Delta q_{t}=\left[\operatorname{sv} q_{t}-(n+\delta+g) k_{t}+k_{t}\right]^{\alpha}\left[(1-v) q_{t}\right]^{1-\alpha}-q_{t}
\end{gathered}
$$

When $\Delta k_{t}=0, \Delta q_{t}=0$, we have:

$$
\begin{gathered}
q_{t}=\frac{n+\delta+g-1}{s v-(1-v)^{\frac{\alpha}{1-\alpha}}} k_{t} \\
q_{t}=\frac{n+\delta+g}{s v} k_{t}
\end{gathered}
$$

For the sake of simplicity, it is assumed that capital has a similar level of contribution to intermediate inputs, ie $\alpha=0.5, \frac{n+\delta+g-1}{s v-(1-v)^{\frac{\alpha}{1-\alpha}}} k_{t}<\frac{n+\delta+g}{s v} k_{t}$ is reduced to: $\frac{n+\delta+g-1}{s v+v-1}<\frac{n+\delta+g}{s v}$

$$
\mathrm{v}<\frac{n+\delta+g}{s+n+\delta+g}
$$

If the above maximum is $\mathrm{W}$ :

$$
\begin{array}{ll}
\frac{\partial \mathrm{W}}{\partial \mathrm{n}}=\frac{s}{(s+n+\delta+g)^{2}} & >0 \\
\frac{\partial \mathrm{W}}{\partial \mathrm{g}}=\frac{s}{(s+n+\delta+g)^{2}} & >0
\end{array}
$$

According to the data from China Statistic Yearbook, the growth rate of the population can be obtained is inversely proportional to the proportion of elderly population and old-age dependency ratio, so the maximum VAR is inversely proportional to the proportion of the elderly population and because the partial derivative of the VAR to technological progress is larger than zero. Therefore, technological progress has promoted the increase of value added rate.

\section{Data Introduction}

An important step of studying the industrial VAR is to measure the industrial VAR in China, mainly because there is very little data on the industrial VAR and it is almost impossible to get the data directly due to the different statistical standards. Therefore, many scholars have used various methods tocalculated the rate. Li Xiaoping (2008) ${ }^{[10]}$ limited the industry sub-sector to 1998-2003. Tu Zhengge (2008) ${ }^{[11]}$ The provincial industrial research period from 1998 to 2005, while avoiding the issue of inconsistency in caliber, also made the analysis not extensive enough to reveal the changing patterns of economy over a longer period of time. Chen Shiyi (2011) ${ }^{[12]}$ has calculated the industrial added value of the entire industry, which solving problem of statistical caliber. However, its research was only conducted in 2008, and after 2008, China don not publish annual value-added data. This in turn has plagued our research. However, the National Bureau of Statistics of China announced the year-on-year and quarter-on-quarter data on the added value of the industry. We draw on the data of the industrial added-value rates for the period 1986-2015 based on the method of Lin Boqiang and Liu Hongxun (2015) ${ }^{[13]}$.

We refer to the data from Zhao Zhiyun and Yang Chaofeng's paper (2011) ${ }^{[14]}$ about total factor productivity and supplement his 2010-2015 data according to his method. Total factor productivity is based on the 1990 base year $(1990=1)$. The rate of population aging is defined as the proportion of the population aged 65 and over.

We estimate the average years of schooling according to the years of schooling of 6 years, 9 years, 12 years and 16 years according to primary, middle school, high school, technical school and college education. The per capita GDP data come from the statistical yearbook and are adjusted based on the price index of $1900=100$. The above data are from the "China Statistic Yearbook", 
"China Industrial Economics Statistical Yearbook", "China Price Statistical Yearbook" and WIND database over the years.

\section{Measurement Analysis}

In order to empirically analyze the effect of population age structure on the rate of industrial added value, we establish the following regression equation:

$$
\mathrm{IVA}=\alpha+\beta_{0} \text { or }+\beta_{1} \text { or }{ }^{2}+\beta_{2} e d u+\beta_{3} \ln r g d p+\beta_{4} t f p+\mu
$$

In equation IVA stands for the rate of industrial VAR; or stands for the population aging rate, which is also added to the equation; edu stands for the average years of schooling; $\ln r g d p$ stands for the logarithm of GDP per capita; $t f p$ stands for total factor productivity; $\mu$ is the residual term representing variables that may affect the industrial VARbut are not reflected in the model.

This paper analyzes the impact of population aging on the industrial VAR, the results are as follows:

\begin{tabular}{|c|c|c|c|c|}
\hline $\begin{array}{l}\text { Explanatory } \\
\text { variables }\end{array}$ & $\begin{array}{l}\text { Industrial } \\
\text { VAR of all } \\
\text { industries }\end{array}$ & $\begin{array}{l}\text { Industrial } \\
\text { VAR of } \\
\text { labor-intensive } \\
\text { industries }\end{array}$ & $\begin{array}{c}\text { Industrial } \\
\text { VAR of } \\
\text { capital-intensive } \\
\text { industries }\end{array}$ & $\begin{array}{c}\text { Industrial } \\
\text { VAR of } \\
\text { technology-inte } \\
\text { nsive industries }\end{array}$ \\
\hline$\alpha$ & $\begin{array}{l}109 * * \\
16.00\end{array}$ & $\begin{array}{c}100.40 * * * \\
(17.81)\end{array}$ & $\begin{array}{c}108.39 * * * \\
(15.49)\end{array}$ & $\begin{array}{c}119.10 * * * \\
(15.77)\end{array}$ \\
\hline or & $\begin{array}{r}17.65 * * \\
(7.76)\end{array}$ & $\begin{array}{c}22.16 * * * \\
(6.63)\end{array}$ & $\begin{array}{r}16.46^{* *} \\
(7.51)\end{array}$ & $\begin{array}{r}16.60 * * \\
(7.64)\end{array}$ \\
\hline$o r^{2}$ & $\begin{array}{r}-0.91 * * \\
(0.40)\end{array}$ & $\begin{array}{c}-1.18 * * * \\
(0.48)\end{array}$ & $\begin{array}{r}-0.84 * * \\
(0.39)\end{array}$ & $\begin{array}{c}-0.835^{* *} \\
(0.40)\end{array}$ \\
\hline$e d u$ & $\begin{array}{l}-0.90 \\
\quad(2.51)\end{array}$ & $\begin{array}{l}-0.17 \\
(2.80)\end{array}$ & $\begin{array}{l}-0 . \\
(2.43)\end{array}$ & $\begin{array}{l}-1.34 \\
\quad(2.47)\end{array}$ \\
\hline $\ln r g d p$ & $\begin{array}{c}-25.00^{* *} \\
(5.22)\end{array}$ & $\begin{array}{l}-27.27 * * * \\
(5.81)\end{array}$ & $\begin{array}{c}-24.07 * * * \\
(5.06)\end{array}$ & $\begin{array}{c}-25.67 * * * \\
(5.15)\end{array}$ \\
\hline$t f p$ & $\begin{array}{l}38.86^{* * *} \\
(13.87)\end{array}$ & $\begin{array}{r}39.56 * * * \\
(15.43)\end{array}$ & $\begin{array}{l}34.10 * * \\
(13.43)\end{array}$ & $\begin{array}{l}36.81 * * \\
(13.67)\end{array}$ \\
\hline$R^{2}$ & 0.59 & 0.51 & 0.61 & 0.66 \\
\hline
\end{tabular}

Note: (1) The values in parentheses are standard deviations; (2) ***, **, * indicate significance at $1 \%, 5 \%$ and $10 \%$ respectively.

From the above empirical results, several conclusions can be drawed:

(1) Regardless of the type of industrial organization, the industrial VAR is the first to increase and then decrease with population aging. Among them, when the proportion of population aging is $9.67 \%, 9.39 \%, 9.73 \%$ and $9.94 \%$, the VAR of all industrial, labor-intensive industries, capital-intensive industries and technology-intensive industries reaches the maximum, .

(2) GDP per capita is inversely proportional to the rate of industrial added value. With the increase of per capita GDP, residents' disposable income will also increase. On the one hand, it can reflect the increase of labor cost and on the other hand promote the upgrade of consumption. The rising labor costs have put a lot of pressure on the development of industries, especially the labor-intensive industries, which will force the profits of some enterprises to drop, which in turn will lead to a decrease in the value-added rate. 
(3) Total factor productivity is positively correlated with the VAR. According to the Solow model, technological progress is a source of sustained economic growth, for the industry. Technological progress is also a source of sustained increases in the rate of industrial added value.

(4) The measurement of this article shows that the relationship between the average years of education and the VAR is small. Probably because the length of the education does not necessarily mean the strength of the work ability. Especially under the current education in China, students have more theories but fewer opportunities to practice so that the knowledge and work they can not perfectly meet. Therefore, the length of education may have a small impact on the VAR.

\section{Conclusion}

Aging is an irreversible trend. The increase of aging will have a negative impact on the industrial VAR of our country. Among them, labor-intensive industries have the most impact, while technology-intensive industries have less impact. At present, China's population aging rate has exceeded the United Nations 7\% standard and has entered an aging population. In the past, China's development over the past few decades relied on China's huge demographic bonus. In the future, as the demographic dividend vanishes, a new economic engine must be created.

Science and technology are primary productive forces, vigorously develop science and technology, encourage scientific and technological innovation, and improve the scientific and technological content of products. To develop technology-intensive industries vigorously is of great importance for raising the industrial VAR of our country. Second, changing the current mode of education to bring education closer to the reality and the enterprise will promote the combination of theory with practice and make better use of what we have learned in technological innovation. This will be the only way.

\section{References}

[1] Shen Lisheng, Wang Heng. What does it mean to increase the rate of value? [J] .Economic Research, 2006 (03): 59-66. (In Chinese)

[2] Keun Lee, Byung-Yeon Kim, Both Institutions and Policies Matter but Differently for Different Income Groups of Countries: Determinants of Long-Run Economic Growth Revisited, World Development. 2009, 37 (3): 533-549

[3] Eric W. K, Tsang, Paul S. 1. Yip, Mun Heng Toh, The impact of R \& D on value added for domestic and foreign firms in a newly industrialized economy, International Business Review. 2008, 17 (4): 423-441

[4] Wu Wenhao. Research on the Characteristics of the Value Added Rate of High-tech Industry in the United States, Japan and South Korea [J]. Science and Technology Management Research, 2013,33 (07): 119-123. (In Chinese)

[5] Higgins M., Williamson J.G. 1997. Age Structure Dynamics in Asia and Dependence on Foreign Capital [J]. Population and Development Change. Demography 32: 543-555.

[6] Luo Laijun, Shi Rui, Chen Yantai, Luo Yuze. Wages, labor costs and industrial upgrading in China [J] .New Economics, 2012 (05): 36-42. (In Chinese)

[7] Cai Fang. Development stage to determine the choice and development strategy - China has reached the stage of heavy chemical industry do? [J]. The dynamics of economics, 2005 (09): 15-19. (In Chinese)

[8] Li Zhong-Jian, Liu Cuixia. Research on the Trend and Quality Structure of Labor Demand in the Process of Manufacturing Upgrading - An Empirical Analysis Based on Gray Theory [J]. Industrial Technology Economics, 2015,34 (02): 117-123. (In Chinese)

[9] Fan Jin, Yuan Xiaohui, Zhang Xiaolan. Main Problems and Their Approaches to Improving the Quality of Economic Growth in China: A Case Study of the Yangtze River Delta Region [J] Journal of Nanjing Social Sciences, 2017 (10): 10-18. (In Chinese) 
[10] Li Xiaoping, Lu Xianxiang, Zhu Zhongdi. International Trade, Technological Progress and Productivity Growth in China's Industrial Sector [J] .Journal of Economics (Quarterly), 2008 (02): 549-564. (In Chinese)

[11] Tu Zhengge. Coordination of Environment, Resources and Industrial Growth [J] .Journal of Economic Research, 2008 (02): 93-105. (In Chinese) 